13,06

\title{
Влияние температуры синтеза на микроструктуру и электрофизические свойства пленок BST 80/20
}

\author{
() М.С. Афранасьев ${ }^{1}$, Д.А. Киселев ${ }^{1,2}$, С.А. Левашов ${ }^{1}$, А.А. Сивов ${ }^{1}$, Г.В. Чучева ${ }^{1, \uparrow}$ \\ ${ }^{1}$ Фрязинский филиал Института радиотехники и электроники им. В.А. Котельникова РАН, \\ Фрязино, Московская обл., Россия \\ ${ }^{2}$ Национальный исследовательский технологический университет «МИСиС», \\ Москва, Россия \\ ๑ E-mail: gvc@ms.ire.rssi.ru
}

Поступила в Редакцию 22 апреля 2019 г.

В окончательной редакции 22 апреля 2019 г.

Принята к публикации 23 апреля 2019 г.

Показано влияние температуры синтеза на микроструктуру и электрофизические свойства сегнетоэлектрических пленок состава $\mathrm{Ba}_{0.8} \mathrm{Sr}_{0.2} \mathrm{TiO}_{3}$ при формировании на кремниевые подложки с подслоем платины. На основе электрофизических и топографических измерений делается вывод о влиянии температуры синтеза сегнетоэлектрических пленок на их свойства.

Ключевые слова: металл-диэлектрик-металл-структуры, сегнетоэлектрические пленки состава $\mathrm{Ba}_{0.8} \mathrm{Sr}_{0.2} \mathrm{TiO}_{3}$, микроструктура, электрофизические свойства, сканирующая зондовая микроскопия.

DOI: $10.21883 /$ FTT.2019.10.48275.463

\section{1. Введение}

Перспективы создания и развития следующих поколений устройств хранения и обработки информации связывают с применением новых, как по составу, так и по структуре, конструкционных материалов. В качестве конструкционного материала большой интерес представляют сегнетоэлектрики. Одним из важных направлений является использование сегнетоэлектриков в качестве изолирующих слоев в структурах металл-диэлектрикметалл (МДМ).

Среди исследуемых сегодня сегнетоэлектриков наиболее привлекательны оксидные материалы со структурой перовскита с общей формулой $A B \mathrm{O}_{3}$. Важная особенность таких веществ - способность образовывать многокомпонентные твердые растворы, что позволяет создавать материалы, электрофизические свойства которых изменяются в широких пределах. Сейчас считается, что наиболее перспективными сегнетоэлектрическими материалами для систем памяти и сверхвысокочастотных приложений представляются твердые растворы титанатов и цирконатов бария, стронция и свинца [1-3]. Пленки титаната бария-стронция (BST) целесообразно использовать в микроэлектронике в качестве материала с высокой диэлектрической проницаемостью (high-k) при переходе к топологическим нормам $90 \mathrm{~nm}$ и менее [4]. Характеристики электронных устройств, принцип действия которых основан на использовании пленок BST, в значительной мере зависят от состава и свойств сегнетоэлектрического слоя. В работе [5] показано, что изменение компонентного состава BST пленок позволяет управлять величиной статической диэлектрической проницаемости, СВЧ-потерями и температурными свойствами пленки. В статье [6] приведены результаты исследований влияния давления рабочего газа в процессе ионно-плазменного распыления на свойства осаждаемых сегнетоэлектрических покрытий титаната бария-стронция. Установлено, что варьирование давления рабочего газа в процессе осаждения пленок BST позволяет менять компонентный состав осаждаемого слоя, что приводит к размытию фазового перехода и улучшению температурной стабильности свойств сегнетоэлектрической пленки [6]. В настоящей работе будет изучено влияние температуры синтеза на микроструктуру и электрофизические свойства сегнетоэлектрических пленок состава $\mathrm{Ba}_{0.8} \mathrm{Sr}_{0.2} \mathrm{TiO}_{3}$.

\section{2. Материалы и методики эксперимента}

Для исследований были приготовлены МДМ-структуры, представляющие собой кремниевую подложку с подслоем платины, сегнетоэлектрическую пленку состава $\mathrm{Ba}_{0.8} \mathrm{Sr}_{0.2} \mathrm{TiO}_{3}$ и верхний электрод из никеля. Сегнетоэлектрическая пленка толщиной $450 \pm 25 \mathrm{~nm}$ наносилась на платиновый электрод методом высокочастотного распыления поликристаллической мишени в атмосфере кислорода на установке Плазма-50СЭ (Россия). Конструкция установки и методика осаждения пленок приведены в $[7,8]$. Температура подложки в процессе синтеза составляла 560 и $620^{\circ} \mathrm{C}$. Верхний электрод из никеля наносился на сегнетоэлектрическую пленку электроннолучевым методом через теневую маску на установке A700QE/DI12000 (Германия). Площадь электродов составляла $2.7 \cdot 10^{-4} \mathrm{~cm}^{2}$, толщина $0.1 \mu \mathrm{m}$. Результаты 
рентгеноскопических исследований подобных образцов представлены в работе [9].

Изучение электрофизических свойств полученных МДМ-структур проведено на измерительном автоматизированном стенде [10] с использованием прецизионного измерителя LCR Agilent E4980A, портативного компьютера с доработанным программным обеспечением и специальной камеры, снабженной нагревательным столиком с термостабилизацией. Эффективная диэлектрическая проницаемость структуры вычислялась по формулам для плоского конденсатора на основе измерений, проведенных по методике, изложенной в работах $[11,12]$.

Топография пленок BST получена в контактном режиме на сканирующем зондовом микроскопе MFP-3D SA (Asylum Research, США) с использованием кантилевера марки Asyelec-02 (Asylum Research, США). Обработка и анализ изображений осуществлялась в программах Gwyddion и WSxM [13].

\section{3. Результаты и обсуждение}

\section{1. Электрофизические свойства}

На рис. 1 приведены вольтфарадные характеристики (ВФХ) пленочных конденсаторов на основе пленок BST, измеренные при комнатной температуре на частоте $100 \mathrm{kHz}$. На образец подавалось напряжение смещения $V_{g}$ от -16 до $+16 \mathrm{~V}$ (кривые 1,3 ) и обратно (кривые 2,4 ), с шагом $0.25 \mathrm{~V}$ и амплитудой измерительного сигнала $25 \mathrm{mV}$ со скоростью считывания данных 3 точки в s.

Электрическое поле усиливает ангармонизм решеточных колебаний в сегнетоэлектрической пленке, что приводит к уменьшению значения ее диэлектрической проницаемости. Максимальные значения емкости для $\mathrm{Pt} / \mathrm{BST} / \mathrm{Ni}$ образцов наблюдались при $V_{g} \approx-1.1 \mathrm{~V}$ для пленок BST, синтезированных при $560^{\circ} \mathrm{C}$, и $V_{g} \approx-0.4 \mathrm{~V}$ для пленок, полученных при $620^{\circ} \mathrm{C}$. Сдвиг максимума относительно точки $V_{g}=0 \mathrm{~V}$ может быть обусловлен присутствием в сегнетоэлектрической пленке внутреннего электрического поля, появление которого связано с различиями в структуре и зарядовом состоянии нижней и верхней межфазных границ $\mathrm{Pt} / \mathrm{BST} / \mathrm{Ni}$ конденсаторов.

Конденсаторы на основе пленок BST, синтезированные при $620^{\circ} \mathrm{C}$, характеризуются более высокими значениями емкости по сравнению с аналогичными МДМ-структурами, полученными при $560^{\circ} \mathrm{C}$. Кривые зависимости емкости от напряжения смещения имеют колоколообразную форму. У образца, синтезированного при $620^{\circ} \mathrm{C}$, пики ВФХ более ярко выражены и симметричны относительно вертикальной оси (см. рис. 1, кривые 1,2 ) кроме того, кривые, описывающие изменение емкости с напряжением и отвечающие разным направлениям измерений ВФХ (прямой ход (кривая 1 ) и обратный ход (кривая 2)), более подобны между собой именно у конденсаторов на основе пленок BST, синтезированных при $620^{\circ} \mathrm{C}$. Это позволяет говорить

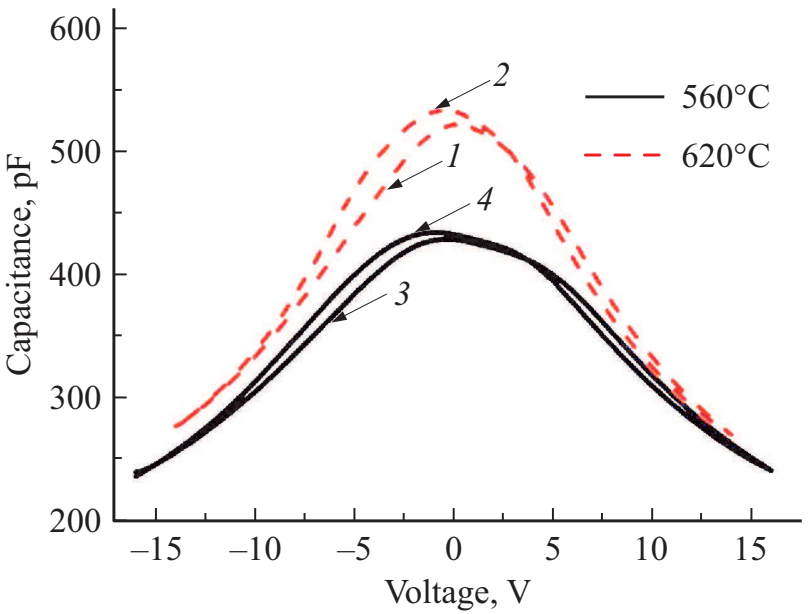

Рис. 1. Зависимость емкости пленочных конденсаторов на основе пленок BST, синтезированных при $560^{\circ} \mathrm{C}$ (кривые 3,4 ) и $620^{\circ} \mathrm{C}$ (кривая 1,2$)$ от напряжения смещения $V_{g}$ при частоте $100 \mathrm{kHz}$ при комнатной температуре.

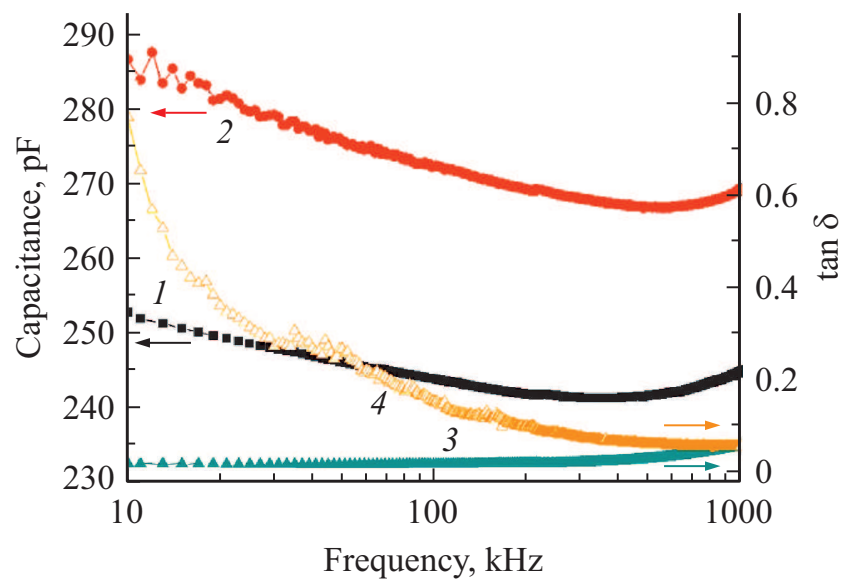

Рис. 2. Частотные зависимости емкости (кривые 1,2) и тангенса угла диэлектрических потерь (кривые 3,4 ) пленочных конденсаторов на основе пленок BST, синтезированных при $560^{\circ} \mathrm{C}(1,3)$ и $620^{\circ} \mathrm{C}(2,4)$, измеренные при напряжении смещения $V_{g}=15.0 \mathrm{~V}$ при комнатной температуре.

о более стабильном поведении структур полученных при $620^{\circ} \mathrm{C}$.

Коэффициент управляемости МДМ-структуры, рассчитанный как отношение емкостей при минимальном и максимальном приложенном поле, достигает значения 1.8 для конденсатора на основе пленки BST, синтезированной при $560^{\circ} \mathrm{C}$ и 1.87 для образца на основе пленки BST, полученной при $620^{\circ} \mathrm{C}$, что также говорит о более высокой управляемости конденсатора на основе пленки, полученной при $620^{\circ} \mathrm{C}$.

На рис. 2 представлены измеренные при комнатной температуре и постоянном смещении $V_{g}=15.0 \mathrm{~V}$ частотные зависимости емкости и тангенса угла диэлектрических потерь Pt/BST/Ni-конденсаторов на основе пленок BST, синтезированных при 560 и $620^{\circ} \mathrm{C}$. 


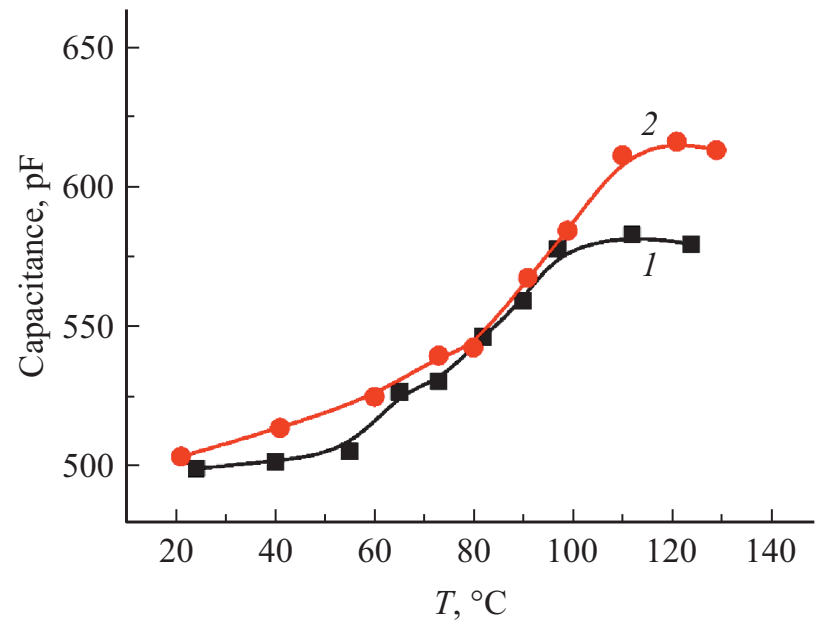

Рис. 3. Температурная зависимость емкости пленочных конденсаторов на основе пленок BST, синтезированных при $560^{\circ} \mathrm{C}$ (кривая 1) и $620^{\circ} \mathrm{C}$ (кривая 2), измеренная при напряжении смещения $V_{g}=0 \mathrm{~V}$ и частоте $100 \mathrm{kHz}$.

C ростом частоты емкости падают в диапазоне частот $10-850 \mathrm{kHz}$, а выше $850 \mathrm{kHz}$ емкости растут для обоих образцов. При этом Pt/BST/Ni-конденсаторы на основе пленок BST, синтезированных при $620^{\circ} \mathrm{C}$ (кривая 2), демонстрируют более высокие значения емкости, чем для образцов на основе пленок BST, полученных при $560^{\circ} \mathrm{C}$ (кривая 1). Тангенс угла диэлектрических потерь для МДМ-структуры на основе пленки BST, синтезированной при $620^{\circ} \mathrm{C}$ (кривая 4 ), имеет резкий спад с частотой на участке $10-500 \mathrm{kHz}$, далее с увеличением частоты падение сильно замедляется (значение тангенса угла наклона касательной составляет около 0.1) и достигает минимального значения при $1 \pm 0.1 \mathrm{MHz}$. Тангенс угла диэлектрических потерь для этого образца падает с 0.75 при $10 \mathrm{kHz}$ до 0.06 при $1 \mathrm{MHz}$. У образцов на основе пленок, синтезированных при $560^{\circ} \mathrm{C}$ (кривая 3), график частотной зависимости тангенса угла диэлектрических потерь имеет вид прямой, параллельной оси абсцисс в диапазоне $10-500 \mathrm{kHz}$, переходящий в незначительный рост в диапазоне $500-1000 \mathrm{kHz}$. Значение тангенса угла диэлектрических потерь составляет 0.02 в диапазоне частот $10-500 \mathrm{kHz}$ и возрастает до значения 0.06 в диапазоне $500-1000 \mathrm{kHz}$.

На рис. 3 представлены температурные зависимости емкости пленочных конденсаторов на основе пленок BST при напряжении смещения равном нулю и частоте $100 \mathrm{kHz}$. Измерения проведены в интервале температур от 20 до $130^{\circ} \mathrm{C}$. При повышении температуры наблюдается рост емкости (соответственно, и рост диэлектрической проницаемости) структуры, причем, участок в диапазоне температур $70-100^{\circ} \mathrm{C}$ характеризуется наиболее стремительным ростом значений. Начиная с температуры $110^{\circ} \mathrm{C}$, рост емкости практически прекращается, изменения значений лежат в пределах измерительной погрешности, и, начиная со $120^{\circ} \mathrm{C}$, наблюда- ется уверенное снижение емкости. Значения емкости для образца на основе пленки BST, синтезированной при $620^{\circ} \mathrm{C}$ (кривая 2), лежат выше, чем для МДМструктуры на основе пленки BST, полученной при $560^{\circ} \mathrm{C}$ (кривая 1). Максимальное значение емкости в МДМструктурах наблюдалось при температуре $T \approx 120^{\circ} \mathrm{C}$.

\section{2. Сканирующая зондовая микроскопия}

На рис. 4 представлены изображения топографии пленок BST, синтезированных при 560 и $620^{\circ} \mathrm{C}$. Статистический анализ показал, что среднеквадратичная шероховатость поверхности $(R m s)$ пленки BST, синтезированной при $560^{\circ} \mathrm{C}$, составила $4.8 \mathrm{~nm}$, а при $620^{\circ} \mathrm{C} \mathrm{Rms}=4.7 \mathrm{~nm}$. Из полученных топографических изображений видно, что пленки сформированы из кристаллитов (зерен). Для количественной оценки размера зерен (корреляционной длины, $\xi$ ) нами использовался метод автокорреляцион-

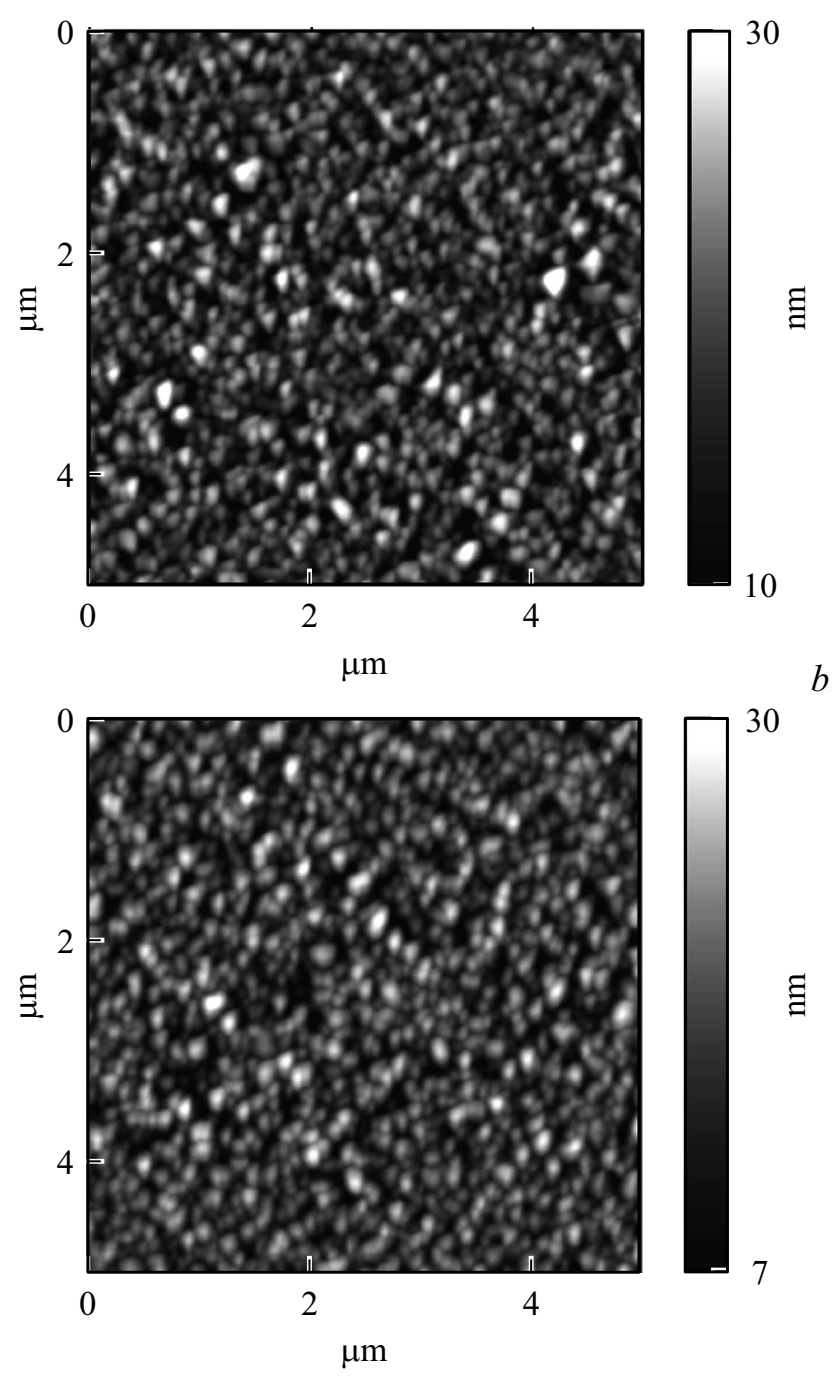

Рис. 4. Изображения поверхности пленок BST, полученных при различных температурах синтеза $\left(a-560^{\circ} \mathrm{C}, b-620^{\circ} \mathrm{C}\right)$. 
$a$
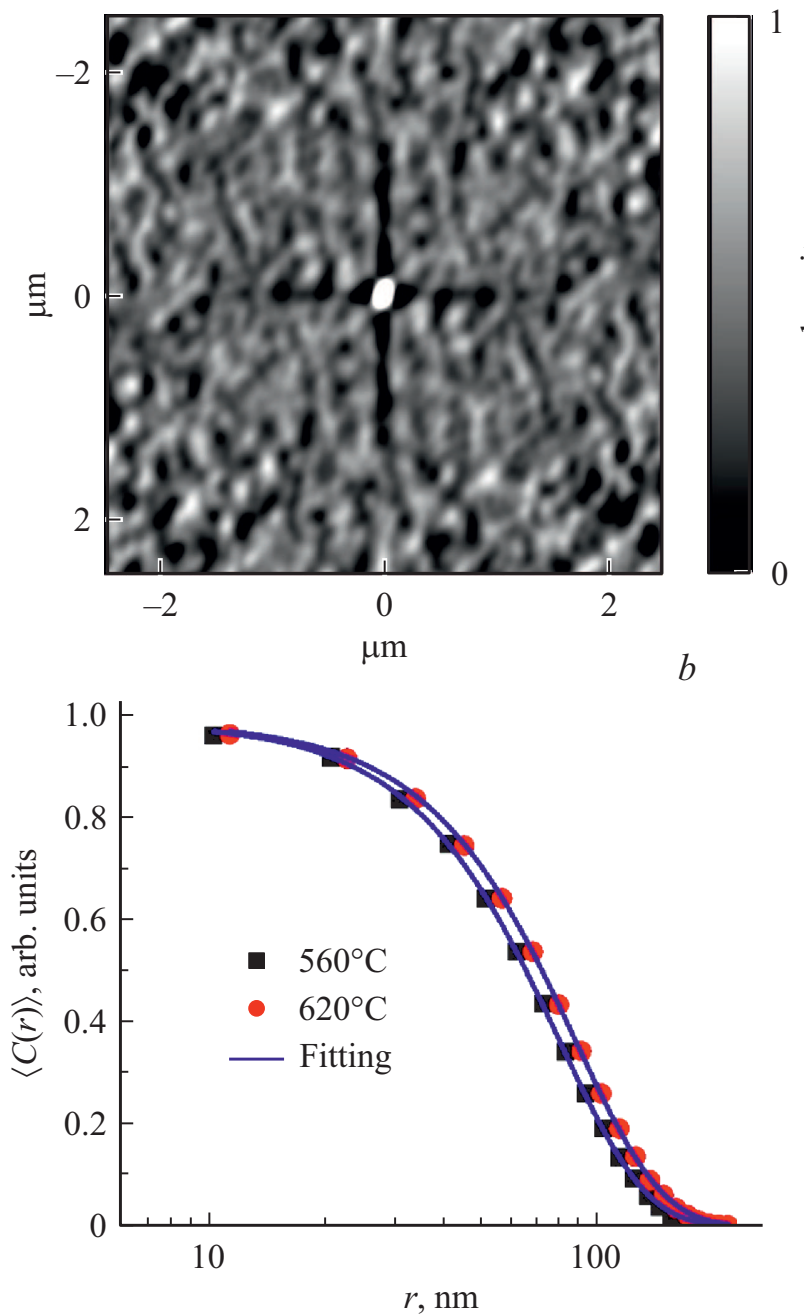

Рис. 5. $2 D$-представление автокорреляционной функции, полученной из топографического изображения поверхности пленки BST $\left(620^{\circ} \mathrm{C}\right)(a)$, на графике $(b)$ представлены профили автокорреляционной функции (точки) и их аппроксимация уравнением (2) (линии) для исследуемых пленок BST.

ной функции [14], которая имеет вид

$$
C\left(r_{1}, r_{2}\right)=\Sigma_{x, y} f(x, y) f\left(x+r_{1}, y+r_{2}\right),
$$

где $f(x, y)$ - матрица изображения (в нашем случае изображения топографии поверхности пленок). Уравнение (1) показывает исходное изображение и смещенное изображение на расстояние $r_{1}$ и $r_{2}$ по осям $X$ и $Y$ относительно центра изображения. Полученное изображение $C\left(r_{1}, r_{2}\right)$, является мерой того, насколько различны эти два изображения. Чем больше схожи исходное изображение и сдвинутое изображение, тем выше значение самокорреляции. Любая периодичность в исходном изображении будет представлять периодическую картину на автокорреляционном изображении. В качестве примера на рис. 5, $a$ приведено $2 D$-представление автокорреляционной функции для пленки BST, синтезированной при $620^{\circ} \mathrm{C}$. Далее, извлекая из полученного автокорреляционного изображения график радиально усредненных значений искомого параметра, можно определить средний размер зерен по площади сканируемой поверхности пленки BST. Для этого используется уравнение вида [14]

$$
\langle C(r)\rangle=A \exp \left[-(r /\langle\xi\rangle)^{2 h}\right],
$$

где $A-$ константа, $r$ - расстояние от центрального пика $(\mathrm{nm})$, определенное из изображения автокорреляционной функции, $\xi-$ среднее значение размера зерна (nm), $h(0<h<1)$ - параметр.

На рис. $5, b$ показаны аппроксимированные зависимости корреляционной функции для определения среднего размера зерен в исследуемых пленках. Расчеты показали, что для BST пленки, синтезированной при $560^{\circ} \mathrm{C}$, средний размер зерен составил $78 \mathrm{~nm}$, а при $620^{\circ} \mathrm{C}$ $\xi=87 \mathrm{~nm}$. Таким образом, температура синтеза оказывает влияние на размер зерен в BST пленках, что, в свою очередь, ведет к повышению диэлектрических характеристик.

\section{4. Заключение}

Проведенные исследования указали на влияние температуры синтеза тонких пленок BST на диэлектрические характеристики МДМ-структур на их основе. Оказалось, что синтезированные при температуре $620^{\circ} \mathrm{C}$ образцы обладают более высокими значениями емкости (и, соответственно, диэлектрической проницаемости) и управляемостью по сравнению со структурами, полученными при $560^{\circ} \mathrm{C}$. Увеличение температуры синтеза также приводит к повышению среднего размера зерна в сегнетоэлектрической пленке.

\section{Финансирование}

Работа выполнена в рамках государственного задания и при частичной поддержке РФФИ (проекты № 18-2911029 и 19-07-00271). Исследования методами сканирующей зондовой микроскопии выполнены при частичной финансовой поддержке Министерства науки и высшего образования РФ на оборудовании ЦКП „Материаловедение и металлургия“ НИТУ «МИСиС» (проект № $11.9706 .2017 / 7.8)$.

\section{Конфликт интересов}

Авторы заявляют, что у них нет конфликта интересов.

\section{Список литературы}

[1] К.А. Воротилов, В.М. Мухортов, А.С. Сигов. Интегрированные сегнетоэлектрические устройства / Под ред. А.С. Сигова. Энергоатомиздат, М. (2011). 175 с.

[2] A.K. Tagantsev, V.O. Sherman, K.F. Astafiev, J. Venkatesh, N. Setter. J. Electroceram. 11, 5 (2003). 
[3] К.М. Рабе, Ч.Г. Ана, Ж.М. Трискона. Физика сегнетоэлектриков. Современный взгляд. БИНОМ. Лаборатория знаний, М. (2011). 440 с.

[4] S. Ezhilvalavan, Tseung-Yuen Tseng. Mater. Chem. Phys. 65, 227 (2000).

[5] А.В. Тумаркин, Е.Р. Тепина, Е.А. Ненашева, Н.Ф. Картенко, А.Б. Козырев. ЖТФ 82, 53 (2012).

[6] А.В. Тумаркин, С.В. Разумов, В.А. Вольпяс, А.Г. Гагарин, А.А. Одинец, М.В. Злыгостов, Е.Н. Сапего. ЖТФ 87, 1585 (2017).

[7] М.С. Афанасьев, М.С. Иванов. ФТТ 51, 1259 (2009).

[8] Д.А. Киселев, М.С. Афанасьев, С.А. Левашов, Г.В. Чучева. ФTT 57, 6, 1134 (2015).

[9] М.С. Афанасьев, Д.А. Киселев, С.А. Левашов, В.А. Лузанов, А.Э. Набиев, В.Г. Нарышкина, А.А. Сивов, Г.В. Чучева. ФТТ 60, 951 (2018).

[10] Е.И. Гольдман, А.Г. Ждан, Г.В. Чучева. ПТЭ 6, 110 (1997).

[11] T. Hamano, D.J. Towner, B.W. Wessels. Appl. Phys. Lett. 83, 5274 (2003).

[12] P.M. Suherman, T.J. Jackson, Y.Y. Tse, I.P. Jones, R.I. Chakalova, M.J. Lancaster, A. Porch. J. Appl. Phys. 99, 104101-1 (2006).

[13] I. Horcas, R. Fernández, J. M. Gomez-Rodriguez, J.W.S.X. Colchero, J.W.S.X.M. Gómez-Herrero, A.M. Baro. Rev. Sci. Instr. 78, 1, 013705 (2007).

[14] R.C. Munoz, G. Vidal, M. Mulsow, J.G. Lisoni, C. Arenas, A. Concha, R. Esparza. Phys. Rev. B 62, 7, 4686 (2000).

Редактор К.В. Емщев 